\title{
Synthesis and analysis of a healable, poly(propylene glycol)-based supramolecular network
}

Article

Accepted Version

Creative Commons: Attribution-Noncommercial-No Derivative Works 4.0

Baker, B. C., German, I. M., Stevens, G. C., Colquhoun, H. M. and Hayes, W. (2019) Synthesis and analysis of a healable, poly (propylene glycol)-based supramolecular network.

Progress in Organic Coatings, 127. pp. 260-265. ISSN 03009440 doi: https://doi.org/10.1016/j.porgcoat.2018.11.029 Available at https://centaur.reading.ac.uk/80965/

It is advisable to refer to the publisher's version if you intend to cite from the work. See Guidance on citing.

To link to this article DOI: http://dx.doi.org/10.1016/j.porgcoat.2018.11.029

Publisher: Elsevier

All outputs in CentAUR are protected by Intellectual Property Rights law, including copyright law. Copyright and IPR is retained by the creators or other copyright holders. Terms and conditions for use of this material are defined in the End User Agreement.

www.reading.ac.uk/centaur 
Central Archive at the University of Reading

Reading's research outputs online 


\title{
Synthesis and Analysis of a Healable, Poly(propylene glycol)-based Supramolecular Network
}

\author{
Benjamin C. Baker ${ }^{\text {a; }}$ Ian M. German ${ }^{\text {b}}$; Gary C. Stevens ${ }^{\text {b; Howard M. Colquhoun }}{ }^{\text {a }}$; and \\ Wayne Hayes ${ }^{\text {a* } *}$ \\ ${ }^{a}$ Department of Chemistry, University of Reading, Whiteknights, Reading, RG6 6AD, UK. \\ ${ }^{\mathrm{b}}$ Gnosys Global Ltd., 17-18 Frederick Sanger Road, The Surrey Research Park, Guildford, \\ Surrey, GU2 7YD, UK
}

Email: w.c.hayes@ reading.ac.uk, Telephone: +44 118378 6491, Fax: +44 1183786331

\begin{abstract}
An investigation into healable supramolecular networks based upon branched poly(propylene) (PPG) oligomers that feature nitroarylurea chain ends is reported. A one-pot reaction utilising bis(toluene-1,4-diisocyanate)-terminated poly(propyleneglycol) $\left(\mathrm{M}_{\mathrm{n}} \sim 2300\right)$, a nitroarylurea recognition motif, and tris(2-aminoethyl)amine was used to synthesise several branched PPG-based oligomers. The degree of oligomerization/branching was systematically varied by changing the stoichiometry of the starting materials in this one-pot reaction. The branched oligomers thus generated self-assemble into supramolecular networks, aided by association of the nitroarylurea end groups, and from this study a material that is capable of healing at ambient temperatures was realised. The healable supramolecular material formed from these studies exhibited effective autonomous healing ( $80 \%$ with respect to ultimate stress) up to 6 weeks after defect formation. Furthermore, elastic recovery was observed (80\% with respect to yield stress) over a period of 24 hours after the samples were elongated beyond the region of uniform strain $(50 \%)$.
\end{abstract}

Keywords: supramolecular network, self-healing, hydrogen bonding, polyurethane ureas

\section{Introduction}

Among the established routes to healable polymeric systems, ${ }^{1-5}$ the reversible formation of supramolecular networks has been shown to be an attractive and successful approach. ${ }^{6}$ Supramolecular networks, typically formed from low molecular weight oligomeric units functionalized with self-assembling motifs, have a distinct advantage over covalently 
crosslinked networks. After damage and disruption of the weak non-covalent associations between constituent oligomers, healing may be achieved via application of a suitable stimulus such as heat, time or pressure. ${ }^{6,7}$ The stimulus promotes molecular motion around the damagesite, thus allowing recognition motifs to re-associate and so reforming the polymer network. Crucially, as it is the weaker supramolecular interactions which break first, the network can undergo multiple break-heal cycles. ${ }^{6}$

Fundamental studies into supramolecular polymer networks which self-assemble through hydrogen bonds have revealed the key design principles required for successful network formation. ${ }^{7-18}$ One approach has utilized molecular motifs with high association constants resulting from well-defined, multiple hydrogen bonding $\left(K_{\mathrm{a}}>10^{6} \mathrm{M}^{-1}\right)$, covalently attached to a variety of polymeric backbones, which self-associate very effectively in the apolar polymer matrix to yield robust elastomeric and dynamic materials. ${ }^{7,9}$ An alternative approach to the creation of supramolecular networks has employed a combination of phase-separation between apolar polymer blocks and self-assembling polar chain-ends. Such systems generally possess less well-defined and far weaker $\left(K_{\mathrm{a}}<250 \mathrm{M}^{-1}\right)$ or more dynamic hydrogen bonds. ${ }^{10-18}$ The networks formed in both approaches can be addressed thermally and importantly exhibit reversible character. These studies have shown that the physical properties of these networks are dependent upon (i) the degree of association of the receptor units, (ii) the 'supramolecular valency, ${ }^{19}$ and (iii) the dynamics of the non-covalent assemblies, ${ }^{15-18}$ in addition to (iv) phase separation between the recognition motifs and the polymer segments. ${ }^{12-18}$ Variation of these structural factors has enabled detailed investigation of the processing temperatures and strength of these supramolecular materials. ${ }^{17-24}$

Developments in understandings of such networks have provided numerous routes to materials that are both mechanically robust as well as healable. ${ }^{7-24}$ A recent example reported by Gooch et $a .^{22}$ describes polyurethane-based elastomers which assemble through triple hydrogen bonding interactions. Gao et al. ${ }^{23}$ have reported healable polyurethane 'cationomers' with a modulus of toughness of approximately $180 \mathrm{MPa}$, suitable for protective roles such as packaging and casing. Burattini et al. ${ }^{24}$ utilised a supramolecular blend formed by combination of hydrogen bonding and $\pi-\pi$ stacking interactions to produce a healable material. More recently, Feula et al. ${ }^{10}$ have developed a hydrogen bonded supramolecular polymer network which permits healing at physiological temperatures (healing after $\sim 1$ hour when held at 37 
${ }^{\circ} \mathrm{C}$ ). This material is biocompatible and thus offers a potential route towards new types of wound dressing.

Herein we report the results from an investigation of some novel supramolecular networks, generated by a one-pot approach using commercially available reagents. The nitroarylurea motif (1 in Scheme 1) has been used successfully to create robust gels from low molecular weight gelators ${ }^{25-29}$ as well as polymer films capable of healing via swelling in aqueous environments. ${ }^{30,31}$ Commercially available tris(2-aminoethyl)amine (2) and bis(toluene-1,4diisocyanate)-terminated poly(propyleneglycol) $\left(\mathrm{M}_{\mathrm{n}}\right.$ 2300) (3 in Scheme 1) were employed as covalent linkers of the self-associating nitroarylurea moiety to form branched oligomers. Based upon the relative nucleophilicity of the amino groups in $\mathbf{1}$ and $\mathbf{2}(\mathbf{2}>\mathbf{1})$, hyperbranched oligomers are formed by the reaction of $\mathbf{2}$ and $\mathbf{3}$ which will then be endcapped by reaction with 1. The branched oligomers are then capable of self-assembling into supramolecular networks by hydrogen bonding between the nitroarylurea end-groups (Scheme 1). Mechanical analysis of such supramolecular networks (4 in Scheme 1) revealed high self-healing and elastomeric recovery properties. ${ }^{5,7,11,22,32}$ 

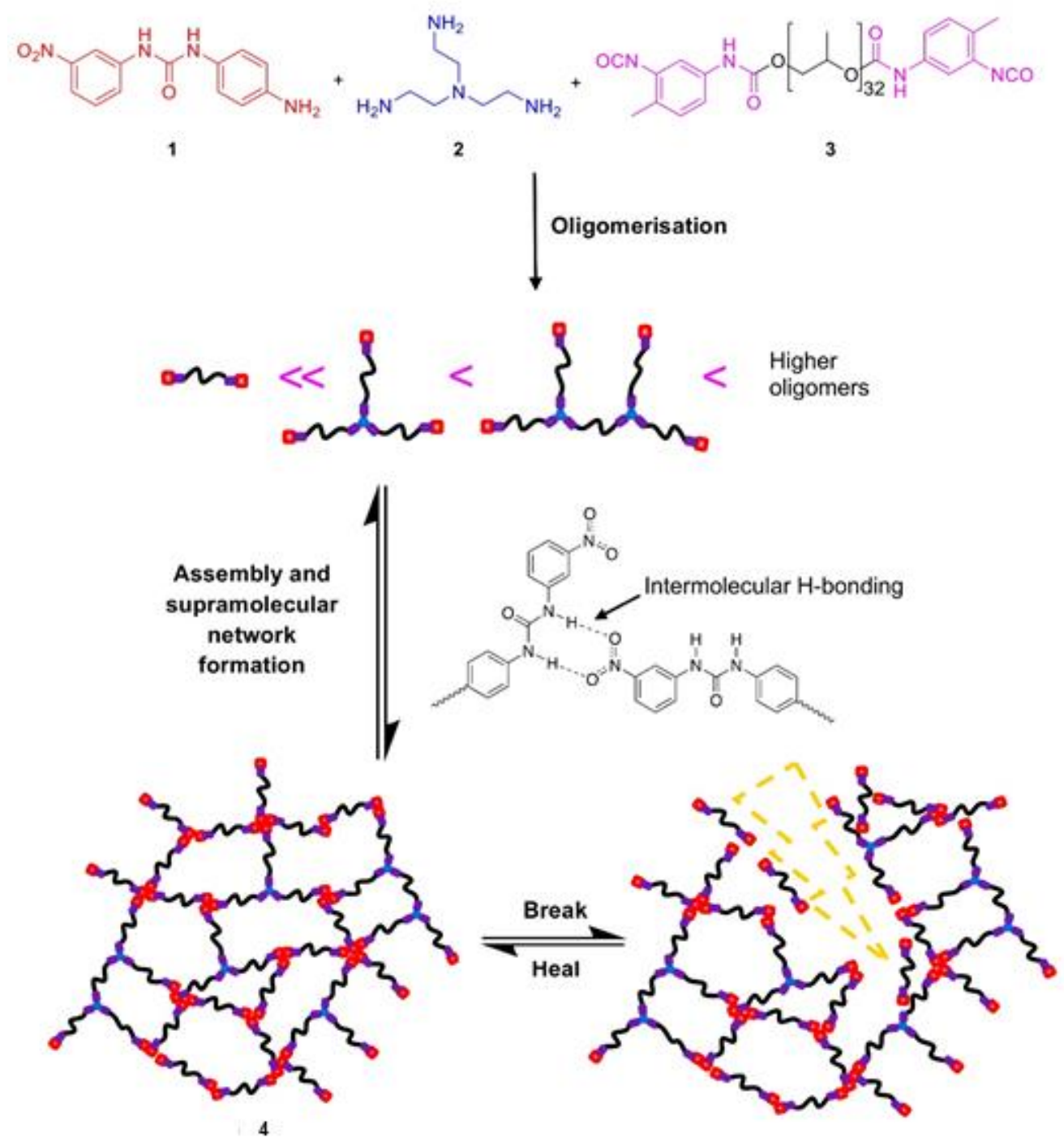

Scheme 1; Schematic representation of the formation of the self-healing supramolecular network 4 from branched oligomers. The mode of assembly between the chain ends involving hydrogen bonding between the nitro- and urea groups is highlighted..$^{25,26}$

\section{Results and Discussion}

\section{Synthesis and Characterisation}

To investigate potential supramolecular networks utilising the self-assembling nitroarylurea system (1), oligomers 4-6 were synthesized (see Table 1) and characterised. Formation of the supramolecular network 4 involved mixing tris(2-aminoethyl)amine (2) and the nitroarylurea (1) in dry THF, followed by addition of bis(toluene-1,4-diisocyanate)-terminated poly(propyleneglycol) $\left(\mathrm{M}_{\mathrm{n}} \sim 2300\right)(3)$. The mixture was then heated to $60{ }^{\circ} \mathrm{C}$ for 2 hours (see Table 1). 
Table 1; The reaction feed ratios to obtain systems 4-7 with respect to molar ratio of reactant added, and inherent viscosities of the products in DMF. Physical form and thermal properties (degradation temperature and glass transition, heating rate $15^{\circ} \mathrm{C} / \mathrm{min}$ ) are also shown. See the Supporting Information (SI) for synthetic procedures and analytical data.

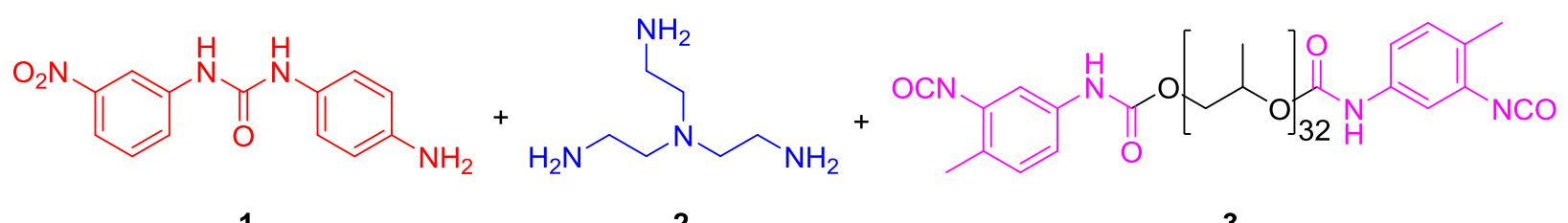

1

2

3

\begin{tabular}{cccccccc}
\hline \multirow{2}{*}{ System } & \multicolumn{3}{c}{$\begin{array}{c}\text { Molar ratio of reactant } \\
\text { added }\end{array}$} & $\begin{array}{c}\eta_{\text {inh }} \\
\left(\mathrm{dL} \mathrm{g}^{-1}\right)\end{array}$ & State & $\begin{array}{c}T_{\text {deg }} \\
\left({ }^{\circ} \mathrm{C}\right)\end{array}$ & $\begin{array}{c}T_{\mathrm{g}} \\
\left({ }^{\circ} \mathrm{C}\right)\end{array}$ \\
\cline { 2 - 6 } & $\mathbf{1}$ & $\mathbf{2}$ & $\mathbf{3}$ & & & & \\
\hline $\mathbf{4}$ & 1 & 1 & 1 & 0.333 & Solid & 272 & -48 \\
$\mathbf{5}$ & 2 & - & 1 & 0.267 & Solid & 254 & -51 \\
$\mathbf{6}$ & - & 1 & 1 & Insol. & Solid & 333 & n.a. \\
$\mathbf{7}$ & - & - & 1 & 0.100 & Viscous oil & 335 & -49 \\
\hline
\end{tabular}

insol = insoluble; n.a. $=$ not available

The monomer ratio in the feed was varied to test the necessity of each of the key structural components in the production of oligomers with healable characteristics (4-7 in Table 1). Selfreaction of bis(toluene-1,4-diisocyanate)-terminated poly(propyleneglycol) $\left(\mathrm{M}_{\mathrm{n}} \sim 2300\right)(3)$ without amine addition (to form 7) was carried out in order to analyse potential chain extension under reaction conditions. Only minimal chain extension of 7 was observed (via ${ }^{1} \mathrm{H}$ NMR spectroscopy, see Figure S4), and the material obtained did not afford stable self-supporting films in contrast to previously reported systems based on di-amines and PPG-di-isocyanate. ${ }^{33}$ The properties of $\mathbf{7}$ highlighted the necessity for both supramolecular interactions between the oligomers formed and molecular weights beyond that of $\mathbf{3}$ as being the determining factors for successful healable film formation.

Structural analysis of the supramolecular network 4 was undertaken using ${ }^{1} \mathrm{H}$ NMR spectroscopy (see Figure S1), with good solubility characteristics demonstrating that no highly covalently crosslinked material was present. ${ }^{12}$ Analysis of the ${ }^{1} \mathrm{H}$ NMR spectrum of the supramolecular network 4 confirmed the successful synthesis of the oligomeric system as demonstrated by the lack of amine resonance $\left(\mathrm{ArNH} \mathrm{H}_{2}\right)$ associated with the nitroarylurea precursor 1. Proton resonances assigned to the para-disubstituted aromatic unit of the nitroarylurea (1) were shifted downfield by 0.53 and $2.54 \mathrm{ppm}$, respectively, indicating that the recognition unit $\mathbf{1}$ had been successfully installed as the end-capping unit on the oligomers. Further analysis of the ${ }^{1} \mathrm{H}$ NMR spectra of the supramolecular network 4 revealed a resonance 
at $5.56 \mathrm{ppm}$ assigned to the $\alpha$-methylene moiety of the tris(2-aminoethyl)amine (2) after oligomer formation, indicating successful incorporation of the tris(2-aminoethyl)amine into the branched oligomers (Scheme 1). In addition, amine-NH proton resonances and N-H stretching absorptions, evident in the ${ }^{1} \mathrm{H}$ NMR and IR spectra, respectively, of hydrolysed bis(toluene1,4-diisocyanate)-terminated poly(propyleneglycol) $\left(\mathrm{M}_{\mathrm{n}} \sim 2300\right)(7)$ (see Figures $\mathrm{S} 4$ and $\mathrm{S} 10$ ) were not observed in the spectra of $\mathbf{4}$, indicating that unreacted monomer was not present in the isolated product and thus demonstrating successful formation of the network.

Comparison of the proton resonance integrals associated with both the PPG backbone ( $c a .3 .81$ ppm, a combination of $\mathrm{CH}_{2}$ and $\mathrm{CH}$ resonances) and the incorporated tris(2-aminoethyl)amine moiety in the ${ }^{1} \mathrm{H}$ NMR spectra of $\mathbf{4}$ enabled the ratio of PPG to tri-armed linker to be determined to be $1.87: 1$. By comparing integrals from the resonances associated with the endcapping nitroarylurea (0.69 with respect to the triarmed linker) a branching factor of 0.51 was calculated. ${ }^{34-37}$ Furthermore, the statistical nature of the branching factor indicates the generation of a randomly branched oligomeric system, rather than a perfectly hyperbranched polymer. ${ }^{36,37}$

In addition to NMR spectroscopic analysis, the infrared spectra of the starting material bis(toluene-1,4-diisocyanate)-terminated poly(propyleneglycol) $\left(\mathrm{M}_{\mathrm{n}} \sim 2300\right)$ (3) and of oligomers 4, 6 and 7 were compared in detail (see SI). The key isocyanate absorption (2273 $\mathrm{cm}^{-1}$ ) associated with the starting material 3 was not evident in the oligomers 4-7 indicating successful urea formation. Furthermore, no amine absorption bands $\left(3682 \mathrm{~cm}^{-1}\right)$ attributable to the starting materials $\mathbf{1}$ and $\mathbf{2}$ and the hydrolyzed PPG $\mathbf{7}$ were present in spectra of 4-6, indicating successful oligomer or network formation. Finally, broad carbonyl stretching bands (ca. $1708 \mathrm{~cm}^{-1}$ ) are present in the spectrum of the branched oligomer $\mathbf{4}$ but not in those of $\mathbf{6}$ or 7, confirming that a range of nitroarylurea moieties exist throughout the material 4.

Comparative GPC analyses of the supramolecular network 4 and the bis-capped PPG 5 were undertaken to establish the degree of oligomerisation in $\mathbf{4}$ (as depicted in Scheme 1). It was found that the supramolecular network 4 exhibits a weak elution peak at a retention time corresponding to the linear, di-capped oligomer 5 (Figure S12). However, the dominant GPC peaks for $\mathbf{4}$ are associated with substantially higher molecular weight materials, indicating that multimodal oligomerization had occurred as a consequence of addition of the tris(2- 
aminoethyl)amine 2. From analysis of the GPC elution peaks, it is evident that the branched oligomers in the supramolecular network 4 contain between zero and three tris(2aminoethyl)amine residues. ${ }^{30-39}$

The nature of the $\mathrm{A}_{2}+\mathrm{B}_{3}$ hyperbranching polymerisation reaction (of 2 with $\mathbf{3}$ ) that was used to generate the supramolecular network 4 presents significant characterization challenges, as recognised for related systems in the literature. ${ }^{9,34}$ For example, attempts to probe the nature of the branched oligomers formed in supramolecular network $\mathbf{4}$ via fluorine tagging resulted in highly insoluble systems. ${ }^{9,12,27,34}$ Such results, (combined with the tensile properties of supramolecular network 4 and covalently crosslinked system 6) indicate that end group phase separation is occurring during supramolecular network formation. ${ }^{12,34,40}$ The self-assembly of these branched oligomers to form a supramolecular network, via association of the nitroarylurea end groups, was also evident from viscosity analysis (Table 1). ${ }^{12,16,29}$ This proposal is supported by the significantly lower inherent viscosity of hydrolysed bis(toluene1,4-diisocyanate)-terminated poly(propyleneglycol) $7\left(\eta_{\text {inh }}=0.100 \mathrm{dL} \mathrm{g}^{-1}\right)$ relative to values for the bis-functionalized $5\left(0.267 \mathrm{dL} \mathrm{g}^{-1}\right)$ and branched oligomer $4\left(0.333 \mathrm{dL} \mathrm{g}^{-1}\right)$.

\section{Mechanical analysis and assessment of healing characteristics}

The supramolecular network $\mathbf{4}$ exhibited healability when the freshly cut and damaged edges of a film were placed in direct, edge-to-edge contact (not overlapped as reported in related studies $^{6-17}$ ) at room temperature for two minutes (see Figure 1). Flexible films of the supramolecular network 4 were produce by solution casting from THF and exhibited a high degree of elasticity as determined by tensile testing. For example, films of dimension $1 \times 3 \times$ $20 \mathrm{~mm}$ were able to withstand a uniform strain $>600 \%$ and a strain to fracture $>800 \%$ at an extension rate of $1 \mathrm{~mm} \min ^{-1}$ : see Figure 1 A. In addition, healing tests were carried out whereby cut samples were left under atmospheric conditions $\left(20^{\circ} \mathrm{C}\right)$ for varying amounts of time before the cut ends were rejoined. It was found that this material retained healability over a period of up to six weeks before the damaged ends were re-engaged (Figure 1 B). Samples of supramolecular network 4 were shown to heal with $>80 \%$ efficiency (with respect to yield stress recovery) throughout the course of this six-week test. Mechanical properties such as energy stored and Young's modulus were not, however, recovered to the same degree $(65 \%$ and $55 \%$, respectively). 

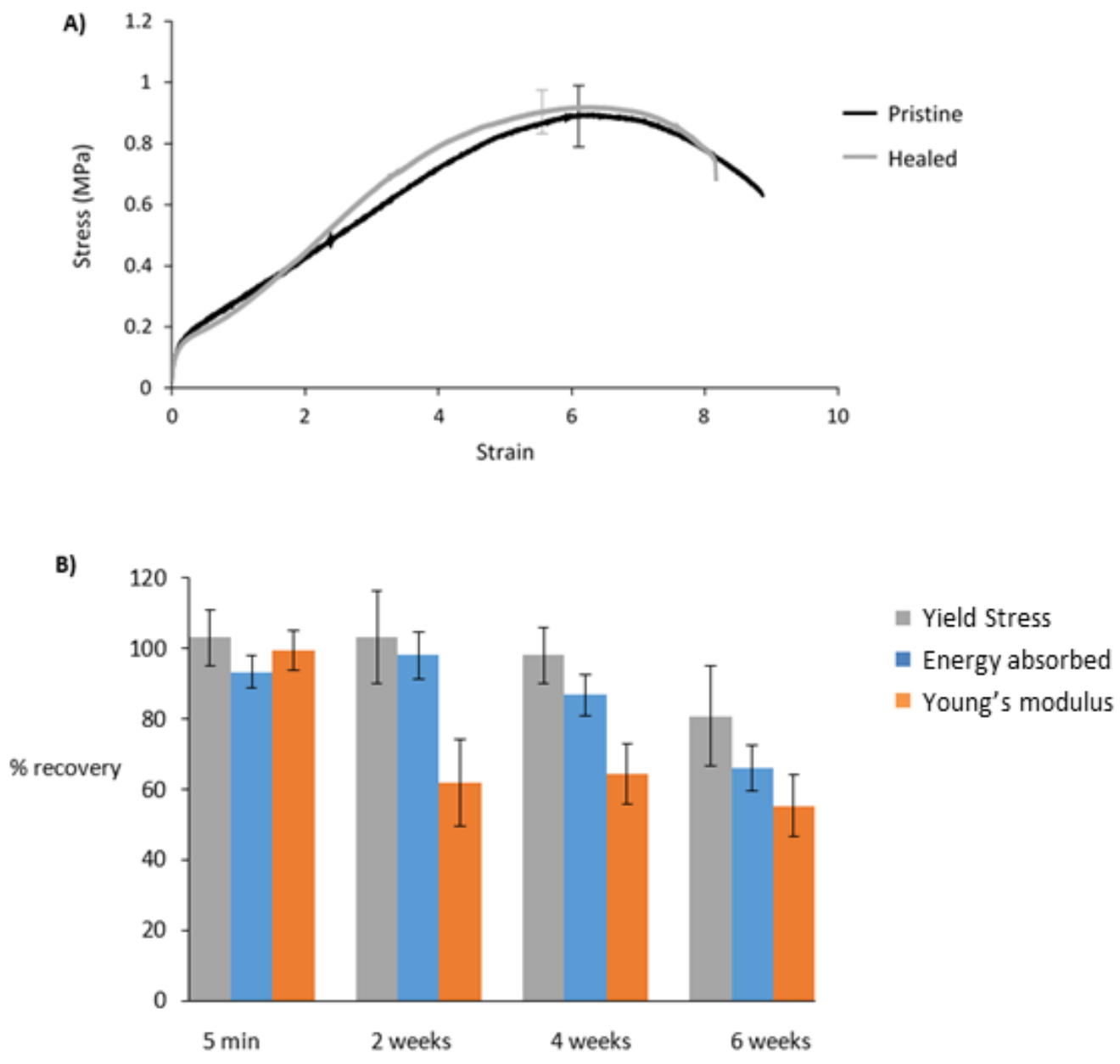

Figure 1 The healability of films of the supramolecular network 4 demonstrated via A) stress-strain graph of pristine films and healed films cut and allowed 2 minutes of contact time; B) percentage healing efficiency (in terms of several mechanical parameters) as a function of time apart after film cutting and separation (for both A

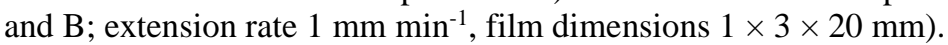

Promisingly, the mechanical strength of the supramolecular network 4 recovered at room temprature $\left(20^{\circ} \mathrm{C}\right)$ in under 30 seconds once the freshly cut film edges were placed in contact (but not overlapped) as shown in Figure 2). It is suggested that such healing ability arises as a result of the dynamic nature of the self-association of the nitro aryl urea motifs. ${ }^{25-28,31}$

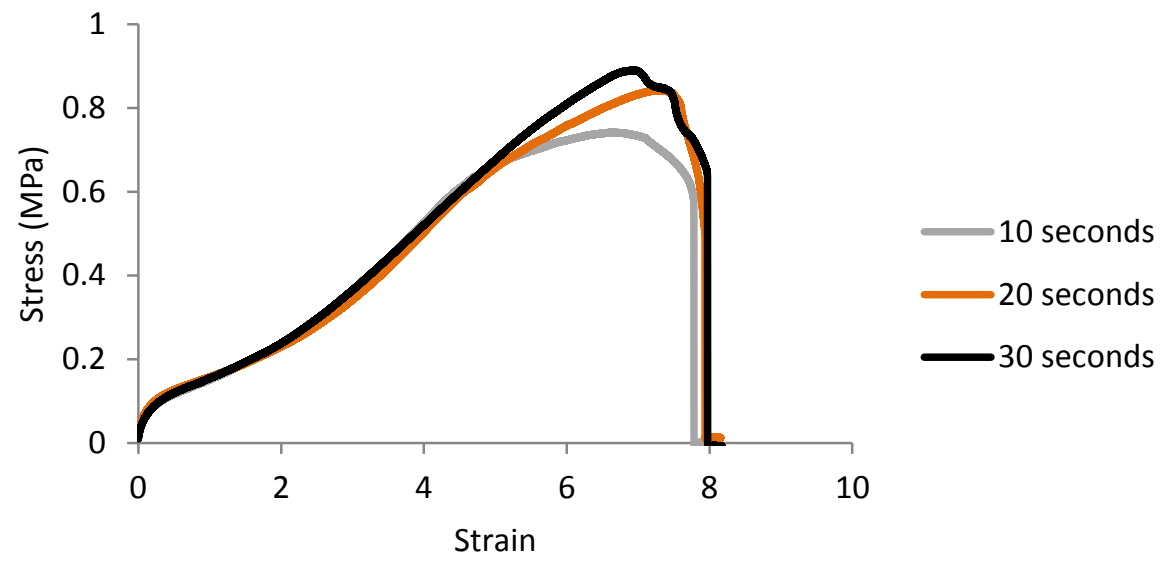


Figure 2 Stress-strain curves of films of supramolecular network 4 as a function of contact time after the film was cut and the edges placed together (extension rate $1 \mathrm{~mm} \mathrm{~min}^{-1}$; film dimensions $1 \times 3 \times 20 \mathrm{~mm}$ ).

In addition, the healable characteristics of the supramolecular network $\mathbf{4}$ were not dependent upon plasticizing additives, unlike several other hydrogen bonded supramolecular polymer networks. ${ }^{12}$ Residual THF or water was not detected in the films of $\mathbf{4}$ via thermogravimetric analysis, either after casting or after being exposed to atmospheric conditions for a period of three months (see Figures S13-14). ${ }^{7,12}$ Interestingly, the higher degradation temperatures observed in samples that were three months old imply that the supramolecular network was still equilibrating to the thermodynamic minimum. It is proposed that the hydrophobicity of the poly(propylene glycol) segments prevents reorientation of the hydrogen-bonding groups away from the cut surface, and hence enables self-healing to be realized for extended periods after defect formation. In less hydrophobic systems, it has been found that end-group reorientation into the bulk after exposure to air can lead to dramatic loss of healability. $8,21,34,38$

The properties of 4 (i.e. defects capable of healing weeks after their formation by mechanical damage) make this system one of potentially high value and impact in the field of self-healing materials. As an example, the healability of the systems could be utilized in coatings for underground cabling and pipework, where accessibility for maintenance is restricted. Defects and system failures (with respect to the polymer protection layer) could be reduced by the healing network, without the need for costly access to the site(s) of damage which may be in remote locations. Furthermore, the observed adhesive qualities of the system in conjunction with the low $T_{\mathrm{g}}$ value of $\mathbf{4}$ would enable facile melt-coating of the wiring found in electrical cabling.

Tensile testing of the films of supramolecular network $\mathbf{4}$ also revealed a high degree of elastic recovery (see Figures S23-S26). The films were able to undergo repeated deformation (at least 3 cycles) at up to $200 \%$ strain with full mechanical recovery (extension rate of $1 \mathrm{~mm} \mathrm{~min}^{-1}$ and compression of $0.1 \mathrm{~mm} \mathrm{~min}^{-1}$ ). However, under applied strains of 300\%, slow deformation was evident on the time scale shown in Figure 3A. After such deformation at strains of up to $200 \%$,the films were able to regain their original mechanical properties (given sufficient time for recovery, typically $<1$ hour), a property not demonstrated in the majority of self-healing materials previously reported. ${ }^{7,12,24}$ 

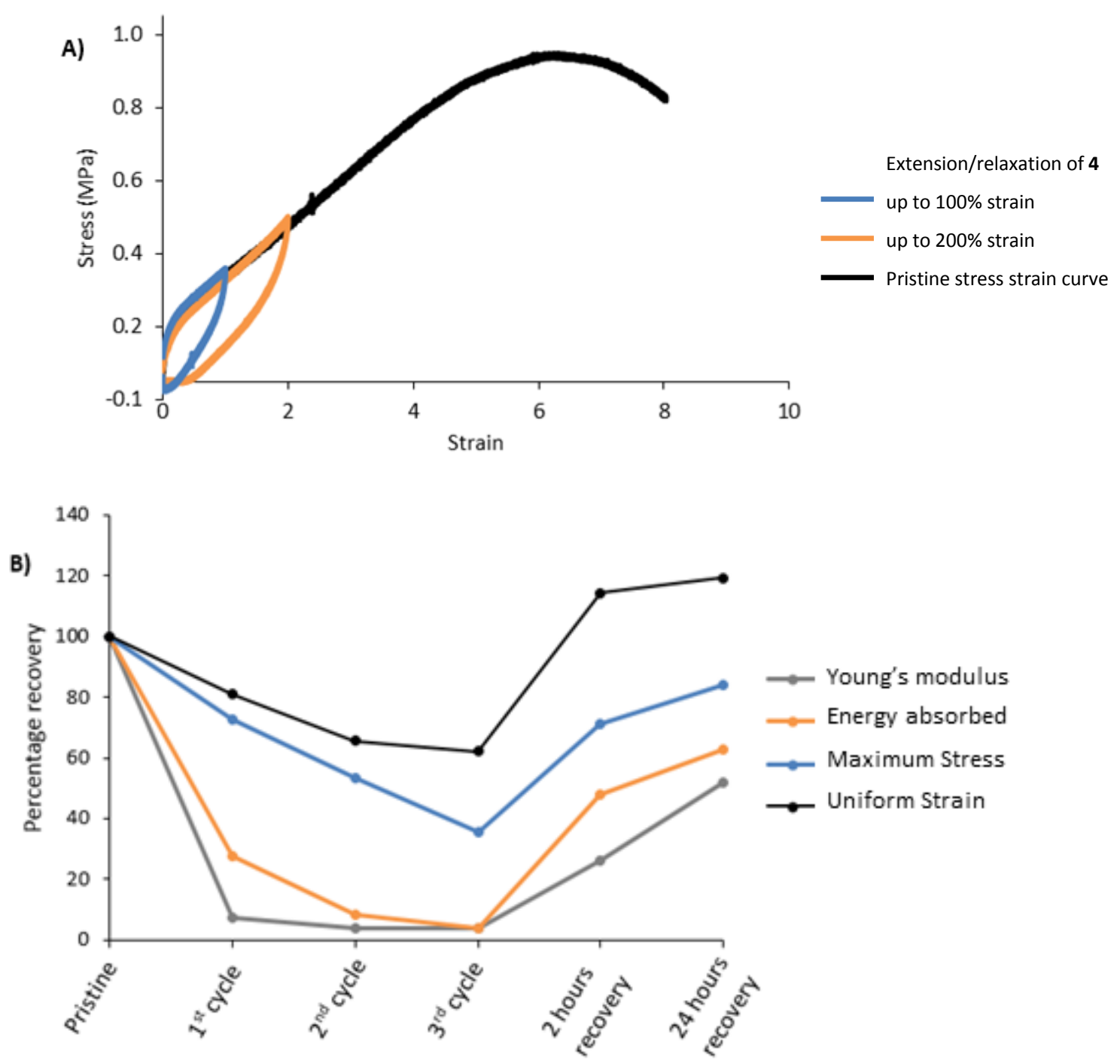

Figure 3: Elastic recovery of $\mathbf{4}$ where A) demonstrates the extension/relaxation of the supramolecular network $\mathbf{4}$, with the same film sample subject to each extension/relaxation cycle (at an extension rate of $1 \mathrm{~mm} \mathrm{~min}^{-1}$ and compression of $0.1 \mathrm{~mm} \mathrm{~min}^{-1}$, and with film thickness $1 \times 3 \times 20 \mathrm{~mm}$ ), and B) elastic recovery of 4 after elongation to $50 \%$ beyond the uniform strain point, as a function of repeat cycles and after a recovery time of two hours.

This observation of high elastic recovery led to investigations of dimensional recovery beyond the linear elastic region, with samples being stretched to $50 \%$ greater than the uniform strain value (without break) and subjected to repeated analysis. It was found that during the first three healing cycles of the films of the supramolecular network $\mathbf{4}$, the mechanical stability of the system was dramatically diminished (Figure 3B). Interestingly, after a recovery time of two hours the film was able to recover fully in terms of yield stress and strain to break, although in these samples the Young's modulus was diminished, suggesting reorientation of functional groups within the network..$^{7,12,21,34}$ This recovery was attributed to the dynamic nature of the 
self-associating nitro aryl urea motif. ${ }^{25-28,31}$ The potential of this system to recover beyond the uniform strain value is of significant importance to the field of self-healing which generally focuses upon defect repair rather than deformation recovery. ${ }^{7,12,24}$

To test the requirement for each starting material 1-3 in the formation of supramolecular networks with healable characteristics, several variations of the reaction procedure were undertaken (Table 1). Mechanical testing and observations of the resulting materials, 4-7, demonstrate the necessity of all three of the reagents in the formation of self-healing networks as realized in 4. It was found that the linear system, 5, did not afford stable films since the product formed was too soft for mechanical analysis. This highlighted the requirement for a degree of covalent chain-extension and branching (realized via the addition of tris(2aminoethyl)amine [2]) in such systems. ${ }^{8,12,19,33,41-42}$ This degree of difference was reflected in the relative thermo-mechanical stabilities of the supramolecular network $\mathbf{4}$ and the linear PPG derivative 5, the latter material exhibiting lower $T_{\mathrm{deg}}$ and $T_{\mathrm{g}}$ values (by $15{ }^{\circ} \mathrm{C}$ and $3{ }^{\circ} \mathrm{C}$, respectively, see Table $\mathbf{1}$ ).

To establish whether or not the nitroarylurea end groups (1) were crucial structural elements for the formation of mechnically stable supramolecular films, a control material was synthesized from poly(propylene glycol) terminated with toluene 2,4-diisocyanate $\left(M_{n} \sim 2300\right)$ (3) and tris(2-aminoethyl)amine (2) in the absence of nitroarylurea end groups (1). This yielded the covalently cross-linked polymer 6 (Table 1). Film casting was attempted from 6 , by evaporating the solvent directly from the gel-like material produced during reaction conditions. However, once dried, the films were confirmed to be insoluble and they did not demonstrate healability even at temperatures $>150{ }^{\circ} \mathrm{C}$. Significantly, it was found that system 6 demonstrated a degree of covalent crosslinking beyond that expected from the reaction stoichiometry. Clearly, addition of the end capping mono amine 1 would prevent chain growth (as it does in the synthesis of 4). However, the molar ratios of reactants used in the synthesis of 6 would be expected to afford a hyperbranched system, similar to the supramolecular network 4, and so affording a soluble material rather than the observed covalently crosslinked polymer.

Films of the crosslinked polymer $\mathbf{6}$ were mechanically weaker with respect to both strain to break, (51\%) and ultimate stress, (89\%) than films cast from the supramolecular network 4 (see Figure S19). It is therefore proposed that the non-covalent crosslinking within systems of the 
supramolecular network 4 strengthens the overall material (with respect to yield point) via the dynamic hydrogen bonding interactions present in the end-group phase, as has been observed in other supramolecular based oligomeric systems. ${ }^{8-24}$ In complete contrast, casting of the hydrolyzed PPG 7 proved unsuccessful, as the resulting film was simply a viscous oil.

\section{Conclusions}

In this paper a novel supramolecular network is reported with autonomous healability at room temperature. The supramolecular network (4) shows a high degree of mechanical recovery after being damaged, and a significant degree of healing can be achieved up to six weeks after the damage event, a result that is in striking contrast to other hydrogen-bonded, non-covalently associated networks. The system also demonstrates elastic recovery beyond the point of uniform strain, if given sufficient recovery time, a property not reported for other established healable polymer systems. The necessity of including each of the three starting materials in the healable supramolecular networks was explored via variations in monomer feed ratios. It was shown that each of the components: the self-associating end group, the polymeric linker and the tri-armed cross-linker, was required in order to form stable healable films. Films could be cast without the self-associating end groups, but the strength of these films and the ability to heal was greatly compromised. The use of the self-assembling nitroarylurea motif to create self-healing materials, as shown in this report, demonstrates the potential for exploitation of other established gelator motifs within polymeric materials in order to generate self-repairing systems. The use of branched and chain-extended oligomeric units to form the supramolecular networks was shown to be necessary, as discrete bis-end-capped systems did yield stable films. The robustness of the system in terms of its mechanical strength and capacity for healing with no external input offers significant potential for systems of this type in applications in remote protection roles such as underground or undersea electrical cabling.

\section{Acknowledgements}

The authors would like to acknowledge financial support from EPSRC and Gnosys Global Ltd (PhD studentship to $\mathrm{BCB}$ ). In addition, EPSRC is acknowledged for funding access to instrumentation in the Chemical Analysis Facility at the University of Reading.

\section{Data Availability}

The supporting information file provides full experimental procedures and analytical data for the polymers reported in this paper. 


\section{References}

1 M. Burnworth, L. Tang, J. R. Kumpfer, A. J. Duncan, F. L. Beyer, G. L. Fiore, S. J. Rowan, C. Weder, Optically healable supramolecular polymers, Nature, 472 (2011) 334-337.

2 M. Hutchby, C. E. Houlden, M. F. Haddow, S. N. G. Tyler, G. C. Lloyd-Jones, K. I. Booker-Milburn, Switching pathways: room-temperature neutral solvolysis and substitution of amides, Angew. Chem. Int. Ed., 51 (2012) 548-551.

3 H. Ying, Y. Zhang, J. Cheng, Dynamic urea bond for the design of reversible and self-healing polymers, Nat. Commun., 5 (2014) 3218-3227.

4 D. K. Kumar, D. A. Jose, A. Das, P. Dastidar, First snapshot of a nonpolymeric hydrogelator interacting with its gelling solvents, Chem. Commun., 66 (2005) 40594061.

5 S. R. White, N. R. Sottos, P. H. Geubelle, J. S. Moore, M. R. Kessler, S. R. Sriram, E. N. Brown, S. Viswanathan, Autonomic healing of polymer composites, Nature, 409 (2001) 794-797.

6 S. Burattini, B. W. Greenland, D. Chappell, H. M. Colquhoun, W. Hayes, Healable polymeric materials: a tutorial review, Chem. Soc. Rev., 6 (2010) 1973-1985.

7 S. H. M. Söntjens, R. P. Sijbesma, M. H. P. Van Genderen, E. W. Meijer, Stability and lifetime of quadruply hydrogen bonded 2-ureido-4[1H]-pyrimidinone dimers, J. Am. Chem. Soc., 122 (2000) 7487-7493.

8 B. Isarea, S. Penseca, M. Raynala, L. Bouteiller, Bisurea-based supramolecular polymers: From structure to properties, C. R. Chim., 19 (2016) 148-156.

9 SupraPolix BV, see http://www.suprapolix.com.

10 A. Feula, X. Tang, I. Giannakopoulos, A. M. Chippindale, I. W. Hamley, F. Greco, C. P. Buckley, C. R. Siviour, W. Hayes, An adhesive elastomeric supramolecular polyurethane healable at body temperature, Chem. Sci., 7 (2016) 4291-4300.

11 A. Feula, A. Pethybridge, I. Giannakopoulos, X. Tang, A. Chippindale, C. R. Siviour, C. P. Buckley, I. W. Hamley, W. Hayes, A thermoreversible supramolecular polyurethane with excellent healing ability at $45^{\circ} \mathrm{C}$, Macromolecules, 48 (2015) 6132-6141.

12 P. Cordier, F. Tournilhac, C. Soulié-Ziakovic, L. Leibler, Self-healing and thermoreversible rubber from supramolecular assembly, Nature, 451 (2008) 977-980.

13 E. Obert, M. Bellot, L. Bouteiller, F. Andrioletti, C. Lehen-Ferrenbach, F. Boué, Both Water- and Organo-Soluble Supramolecular Polymer Stabilized by Hydrogen- 
Bonding and Hydrophobic Interactions, J. Am. Chem. Soc., 129 (2007) 1560115605.

14 M. Müller, A. Dardin, U. Seidel, V. Balsamo, B. Iván, H. W. Spiess, R. Stadler, Junction Dynamics in Telechelic Hydrogen Bonded Polyisobutylene Networks, Macromolecules, 29 (1996) 2577-2583.

15 A. M. S. Kumar, S. Sivakova, J. D. Fox, J. E. Green, R. E. Marchant, S. J. Rowan, Molecular Engineering of Supramolecular Scaffold Coatings that Can Reduce Static Platelet Adhesion, J. Am. Chem. Soc., 2008, (4) 1466-1476.

16 X. Tang, A Feula, B. C. Baker, K. Melia, D. Hermida Merino, I. W. Hamley, C. P. Buckley, W. Hayes, C. R. Siviour, A Dynamic Supramolecular Polyurethane Network whose Mechanical Properties are Kinetically Controlled, Polymer, 133 (2017) 143150.

17 F. Tian, D. Jiao, F. Biedermann, O.A. Scherman, Orthogonal switching of a single supramolecular complex, Nat. Commun., 3 (2012) 1207-1213.

18 a) W. C. Yount, D. M. Loveless, S. L. Craig, Strong Means Slow: Dynamic Contributions to the Bulk Mechanical Properties of Supramolecular Networks, Angew. Chem. Int. Ed., 44 (2005) 2746 -2748. b) J. D. Fox, S. J. Rowan, Supramolecular Polymerizations and Main-Chain Supramolecular Polymers, Macromolecules, 42 (2009) 6823-6835.

19 L. R. Hart, J. H. Hunter, N. A. Nguyen, J. L. Harries, B. W. Greenland, M. E. Mackay, H. M. Colquhoun, W. Hayes, Multivalency in healable supramolecular polymers: the effect of supramolecular cross-link density on the mechanical properties and healing of non-covalent polymer networks, Polym. Chem., 5 (2014) 3680-3688.

20 A. H. Tullo, Stretching tires' magic triangle, Chemical \& Engineering News, 87 (2009) 10-14.

21 Y. Yang, M. W. Urban, Self-healing polymeric materials, Chem. Soc. Rev., 42 (2013) 7446-7467.

22 A. Gooch, C. Nedolisa, K. A. Houton, C. I. Lindsay, A. Saiani, A. J. Wilson, Tunable Self-Assembled Elastomers Using Triply Hydrogen-Bonded Arrays, Macromolecules, 45 (2012) 4723-4729.

23 R. Gao, M. Zhang, S. W. Wang, R. B. Moore, R. H. Colby, T. E. Long, Polyurethanes containing an imidazolium diol-based ionic-liquid chain extender for incorporation of ionic-liquid electrolytes, Macromol. Chem. Phys., 214 (2013) 1027-1036. 
24 S. Burattini, B. W. Greenland, D. H. Merino, W. Weng, J. Seppala, H. M. Colquhoun, W. Hayes, M. E. Mackay, I. W. Hamley, S. J. Rowan, A healable supramolecular polymer blend based on aromatic $\pi-\pi$ stacking and hydrogen-bonding interactions, $\mathrm{J}$. Am. Chem. Soc., 132 (2010) 12051-12058.

25 F. Rodriguez-Llansola, B. Escuder, J. F. Miravet, D. Hermida-Merino, I. W. Hamley, C. J. Cardin, W. Hayes, Selective and highly efficient dye scavenging by a pHresponsive molecular hydrogelator, Chem. Commun., 46 (2010) 7960-7962.

26 D. M. Wood, B. W. Greenland, A. L. Acton, F. Rodríguez-Llansola, C. A. Murray, C. J. Cardin, J. F. Miravet, B. Escuder, I. W. Hamley,W. Hayes, pH Tunable Hydrogelators for Water Purification: Structural Optimisation and Evaluation, Chem. Eur. J., 18 (2012) 2692-2699.

27 N. Bajaj, L. R. Hart, B. W. Greenland, W. Hayes, Urea Organogelators: Synthesis and Properties, Macromol. Symp., 329 (2013) 118-124.

28 B. C. Baker, A. L. Acton, G. C. Stevens, W. Hayes, Bis amide-aromatic-ureasd highly effective hydro- and organogelator systems, Tetrahedron, 70 (2014) 8303-8311.

29 J. W. Steed, Anion-tuned supramolecular gels: a natural evolution from urea supramolecular chemistry, Chem. Soc. Rev., 39 (2010) 3686-3699.

30 J. Hentschel, A. M. Kushner, J. Ziller, Z. Guan, SelfHealing Supramolecular Block Copolymers, Angew. Chem. Int. Ed., 51 (2012) 10561-10565.

31 B. C. Baker, I. M. German, A. M. Chippindale, C. E. A. McEwan, G. C. Stevens, H. M. Colquhoun, W. Hayes, Nitroarylurea-terminated supramolecular polymers that exhibit facile thermal repair and aqueous swelling-induced sealing of defects, Polymer, 140 (2018) 1-9.

32 X. Chen, M. A. Dam, K. Ono, A. Mal, H. Shen, S. R. Nutt, K. Sheran, F. Wudl, A thermally re-mendable cross-linked polymeric material, Science, 295 (2002) 16981702.

33 J. M. Lehn, N. Roy, European Patent Office, Patent No; EP 2829561 A1, $(28 / 01 / 2015)$.

34 B. Greenland, W. Hayes, Healable Polymer Systems, Royal Society of Chemistry, Cambridge, 2013.

35 M. Liu, N. Vladimirov, J. M. J. Fréchet, A New Approach to Hyperbranched Polymers by Ring-Opening Polymerization of an AB Monomer: 4-(2-Hydroxyethyl)ع-caprolactone, Macromolecules, 32 (1999) 6881-6884. 
36 B. Voit, New developments in hyperbranched polymers, J. Polym. Sci. Part A Polym. Chem., 38 (2000) 2505-2525.

37 K. Inoue, Functional dendrimers, hyperbranched and star polymers, Prog. Polym. Sci., 25 (2000) 453-571.

38 M. A. Ward, T. K. Georgiou, Thermoresponsive Polymers for Biomedical Applications, Polymers, 3 (2011) 1215-1242.

39 R. Spindler, J. M. J. Fréchet, Synthesis and characterization of hyperbranched polyurethanes prepared from blocked isocyanate monomers by step-growth polymerization, Macromolecules, 26 (1993) 4809-4813.

40 M. Jikei, S. H. Chon, M. Kakimoto, S. Kawauchi, T. Imase, J. Watanabe, Synthesis of hyperbranched aromatic polyamides, Macromolecules, 32 (1999) 2061-2064.

41 R. P. Sijbesma, F. H. Beijer, L. Brunsveld, B. J. Folmer, J. H. Hirschberg, R. F. Lange, J. K. Lowe, E. W. Meijer, Reversible polymers formed from self-complementary monomers using quadruple hydrogen bonding, Science, 278 (1997) 1601-1604.

42 J. M. Lehn, Supramolecular Chemistry: Concepts and Perspectives, VHC, Weinheim, 1996. 